\title{
O trabalho e a dura realidade dos catadores de material reciclável no município de Sinop, Mato Grosso
}

\author{
Terezinha Gertrudes Lima Rosa*, Claudia Zangrande**
}

*Discente do curso de Graduação em Enfermagem na Faculdade de Ciências Sociais Aplicadas de Sinop (FACISAS), UNIC Sinop Aeroporto, ${ }^{* *}$ Enfermeira, Professora do Curso de Enfermagem da Faculdade de Ciências Sociais Aplicadas de Sinop (FACISAS), UNIC Sinop Aeroporto, Especialista em Saúde Coletiva com Enfase em PSF e Enfermagem do Trabalho

\begin{abstract}
Resumo
O rápido e desordenado crescimento da população urbana resultou em aumento da produção de resíduos sólidos depositados em locais inadequados, trazendo riscos à saúde humana e ambiental. Entretanto, trabalhadores encontram na coleta a única fonte de renda. O objetivo do estudo foi identificar o perfil epidemiológico dos catadores de material reciclável do município de Sinop/MT, bem como demonstrar as práticas desenvolvidas e as condiçôes de trabalho neste local. Tratou-se de um estudo de caso com abordagem qualitativa e quantitativa desenvolvido com 24 catadores de material reciclável. Utilizou-se de um questionário semiestruturado, as respostas transcritas na íntegra, para posterior análise e discussão. Utilizou-se da observação participante e fotografias. Para os dados quantitativos utilizou-se da estatística simples e os dados qualitativos foram submetidos à análise temática de conteúdo. Pode-se observar entre os catadores uma pequena predominância do sexo masculino, idade entre 20 e 62 anos, baixo grau de escolaridade, a grande maioria com união conjugal estável e satisfeito com o faturamento mensal decorrente da atividade. Existe enorme precariedade das condiçóes de trabalho e segurança, exigindo do poder público maior envolvimento no sentido de implantação da Política Nacional de Resíduos Sólidos e dos gestores de saúde ações voltadas a essa população.
\end{abstract}

Palavras-chave: catadores, resíduos sólidos, reciclagem, saúde.

\section{Abstract}

\section{The work and the harsh reality of waste pickers in the city of Sinop, Mato Grosso}

The rapid and unplanned growth of urban population has resulted in increased production of solid waste deposited in inappropriate places, bringing risks to human health and the environment. However, workers have in the collection of this waste the only source of income. This study aimed to identify the epidemiological profile of waste pickers in the city of Sinop/MT, as well as to demonstrate the developed practices and working conditions at this location. This was a case study with qualitative and quantitative approach developed with 24 collectors of recyclable material. For data collection 
was used a semi-structured questionnaire, the responses transcribed for further analysis and discussion. We used participant observation and photography. For the quantitative data we used simple statistics and qualitative data were submitted to thematic content analysis. It can be observed among the collectors a small predominance for males, 20 to 62 years old, low level of education, the vast majority with stable marital union and happy with the monthly turnover resulting from the activity. There are huge precarious working and safety conditions, demanding the government more involved towards implementation of National Politics of Solid Waste and health managers actions directed to this population.

Key-words: solid waste segregators, solids wastes, recycling, health.

\section{Resumen}

\section{El trabajo y la dura realidad de recolectores de materiales reciclables en la ciudad de Sinop, Mato Grosso}

El rápido y desordenado crecimiento no planificado de la población urbana se ha traducido en un aumento de la producción de residuos sólidos depositados en lugares inapropiados, trayendo riesgos para la salud humana y el medio ambiente. Sin embargo, los trabajadores encuentran en la recogida de estos residuos la única fuente de ingresos. Este estudio tiene como objetivo identificar el perfil epidemiológico de los recicladores en la ciudad de Sinop/MT, así como demostrar las prácticas desarrolladas y las condiciones de trabajo en este lugar. Este fue un caso de estudio con enfoque cualitativo y cuantitativo desarrollado con 24 colectores de material reciclable. Para la recolección de datos se utilizó un cuestionario semi-estructurado, las respuestas transcritas para su posterior análisis y discusión. Se utilizó la observación participante y la fotografía. Para los datos cuantitativos se utilizaron los datos estadísticos y cualitativos simples que fueron sometidos a análisis de contenido temático. Se puede observar entre los recolectores un pequeño predominio de los varones, edad entre 20 a 62 años, bajo nivel de educación, la gran mayoría con la unión civil estable y feliz con la facturación mensual resultante de la actividad. Existe enorme precariedad y seguridad en las condiciones de trabajo, que exigen mayor envolvimiento del gobierno en la aplicación de la PNRS (Política Nacional de Resíduos Sólidos), y de los gestores acciones de salud dirigidas a esta población.

Palabras-clave: segregadores de residuos sólidos, residuos sólido, reciclaje, salud.

\section{Introdução}

Dados da Organização das Nações Unidas (ONU) apontam que metade da população mundial vive em regióes urbanas. No Brasil este valor se eleva para uma taxa de $85 \%$, e, decorrente deste desordenado crescimento das cidades em tamanho e população, há um aumento dos problemas associados ao modo de produçáo e consumo, tem-se como resultado uma farta produção de resíduos sólidos, tanto em quantidade quanto em diversidade, contendo elementos perigosos ao ecossistema e a saúde humana [1].

A maneira como esses resíduos são descartados revela um sério problema em saúde pública, pois, não há destino sanitário e ambiental adequado em mais da metade dos municípios brasileiros, sendo depositados em vazadouros a céu aberto, os chamados lixões, [2]. Os lixôes são definidos pelo Instituto Brasileiro de Geografia e Estatística (IBGE) [3] como "locais utilizados para disposição do lixo, em bruto, sobre o terreno sem qualquer cuidado ou técnica especial, sem medidas de proteção ao meio ambiente ou à saúde".
Para Prates [4] o lixo é um problema que não se limita apenas aos países subdesenvolvidos ou em desenvolvimento, o grande volume e a contaminação são alvos de programas de gerenciamento, segregação e reciclagem. Os hospitais e clínicas produzem diariamente uma fartura de resíduos sólidos, resultantes de atividades diversificadas, como: diagnóstico, tratamento, assistência prestada aos pacientes e também os procedentes da área administrativa, de manutenção e da produçáo de alimentos.

Em 2010, foi aprovada a Política Nacional de Resíduos Sólidos (PNRS), o que caracterizou um grande avanço para a política ambiental brasileira [5]. Ao instituir normas que abrangem o gerenciamento de resíduos sólidos, a nova legislação predispóe as antigas demandas obtidas não apenas por ecologistas, mas por toda a coletividade civil, diante do acúmulo potencial de dejetos em áreas urbanas e rurais [6].

No Brasil, segundo dados da Política Nacional de Saneamento Básico (PNSB) são coletados diariamente entre 180 e 250 mil toneladas de resíduos sólidos urbanos e na maioria das vezes tendo apenas 
o lixão como destino final. No ano de 2000, 59\% dos municípios contavam apenas com o lixáo para o descarte dos resíduos sólidos, caindo para 50,8\% no ano de 2010 [1]. A PNRS tem por objetivo que todos os municípios brasileiros organizem um plano municipal de gerenciamento de resíduos sólidos com intuito de que os catadores sejam alcançados e inseridos por meio de estratégias para reintegração social [6].

A reciclagem de lixo caracteriza-se como alternativa eficaz no que tange ao reaproveitamento de materiais descartados, além de ser a única fonte de renda para inúmeros trabalhadores que encontram nesta atividade subsídios para a sobrevivência. Entretanto, considerada insalubre devido ao próprio ambiente e as condiçóes de trabalho, além da exclusão social, pois são homens e mulheres, ainda vistos como desocupados, sujos, abaixo da linha de pobreza, considerados como peças descartáveis para a sociedade $[7,8]$.

Em decorrência do não uso de barreiras de proteção adequadas, estes trabalhadores expóem-se constantemente a queimaduras, dermatites, intoxicaçôes alimentares, doenças parasitárias, tétano, doenças pulmonares e infecto contagiosas como hepatites virais e AIDS [9]. Os agentes presentes nos resíduos sólidos que acarretam risco à saúde humana e ambiental são classificados como: agentes físicos, químicos e biológicos [10].

Para diminuir o risco da exposição a estes agentes, se faz necessário o uso dos Equipamentos de Proteção individual (EPIs), caracterizados como, todo e qualquer objeto de uso individual utilizado pelo trabalhador, destinado à sua proteção, sendo eles, botas, luvas, capacetes, máscaras, óculos de proteçáo, roupas adequadas, uso de protetor solar, entre outros de acordo com a atividade desenvolvida [11].

Por se tratar de uma atividade que acarreta riscos à saúde física e mental e baseado na melhoria de sua execução o enfermeiro entra com papel fundamental na transmissáo de informaçóes relacionadas à importância do uso de EPI, das medidas de higiene e prevenção de doenças infecto contagiosas, contribuindo assim, para um melhor e maior conhecimento dos trabalhadores sobre os riscos a que estáo expostos e consequentemente trazer melhorias à saúde dos mesmos [4]. Ainda, diante de um cenário de vulnerabilidade e exclusão social, justifica-se a escolha da temática pelo fato de existir poucos estudos desta natureza em nosso estado e por ser uma ocupaçáo crescente e ainda muito negligenciada pelas autoridades públicas, pois são escassos os municípios que implantaram a PNRS.

Sendo assim, este trabalho teve como objetivo identificar o perfil dos catadores de material reciclável do município de Sinop/MT, bem como demonstrar as práticas desenvolvidas e as condiçóes de trabalho neste local.

\section{Material e métodos}

Tratou-se de um estudo de caso, com abordagem qualitativa e quantitativa, que buscou analisar o perfil epidemiológico dos catadores de material reciclável, bem como retratar das condiçóes de trabalho no lixão do município de Sinop. Localizado ao noroeste da regiáo Centro-Oeste do Brasil, Norte Mato-Grossence, na latitude de 11050'53" Sul e longitude de $55^{\circ} 38^{\prime} 57^{\prime \prime}$ Oeste, Sinop possui uma área de $3.942,231 \mathrm{~km}^{2}$, o Bioma é Amazônico e uma população de 113.099 habitantes [12]. Município este que ainda náo conta com a coleta de lixo de forma seletiva, todo lixo coletado é despejado no lixão municipal, localizado na estrada Jacinta, zona rural. O estudo foi realizado nos meses de janeiro a fevereiro de 2015, após autorização do presidente da Associação dos Catadores de Materiais Recicláveis de Sinop (ACAMARES), e aprovação pelo Comitê de Ética em Pesquisa da Universidade de Cuiabá - UNIC sob parecer número 925.598. No primeiro encontro foi explicado sobre os objetivos e desenvolvimento do estudo, em seguida solicitado o preenchimento do Termo de Consentimento Livre e Esclarecido (TCLE), dessa forma tomou-se os cuidados mencionados nas Diretrizes e Normas Regulamentadoras de Pesquisa com Seres Humanos, aprovados pela Resoluçáo CNS 466/12. Os demais encontros aconteceram para a realização das entrevistas, observaçáo do trabalho, e realização de imagens fotográficas, retratando o local e as condiçôes de trabalho dos catadores.

A populaçáo do estudo foi composta por catadores de material reciclável, pertencentes à associação de catadores e que consentiram voluntariamente em participar da pesquisa, assinando o TCLE, os mesmos foram identificados pelas iniciais de seus nomes. Não foram utilizados como critérios de inclusão ou exclusão, raça, sexo, escolaridade, estado civil ou renda, excluiu-se do estudo aqueles com idade menor a 18 anos e o fato de o participante não consentir em participar voluntariamente $\mathrm{da}$ pesquisa negando-se em assinar o TCLE. 
Para a coleta de dados foi utilizada à entrevista tendo como base um questionário semiestruturado, as respostas foram transcritas na íntegra pelo pesquisador, para posterior análise, ainda utilizou-se da observação participante e imagens fotografias. Os dados quantitativos foram analisados por meio da estatística simples, demonstrados em gráficos e tabelas com frequência absoluta e relativa e os dados qualitativos submetidos à análise temática, uma das modalidades de análise de conteúdo, fundamentada na regularidade das afirmaçóes, que busca revelar, estruturas de relevância, valores de referência e comportamentos [13].

\section{Resultados e discussão}

Dos 32 catadores de material reciclável integrantes da ACAMARES, 24 (75\%) aceitaram em participar do estudo, enquanto que 8 (25\%) recusaram-se por motivos variados, dentre eles a falta de ônus pela participação. A média de idade obtida foi de 38,2 anos, com variação entre 21 e 62 anos, maior predomínio entre os 20 e 40 anos (62,5\%), assemelhando-se a outro estudo no qual a predominância ficou entre 25 e 45 anos com $(52,2 \%)$ [14]. Quanto ao sexo, $13(54,2 \%)$ eram homens e $11(45,8 \%)$ mulheres, 14 (58,3\%) possuem ensino fundamental incompleto, a maioria considera-se pardo com $13(54,2 \%), 10(41,7 \%)$ relatam ser casados (Tabela I).

Tabela I - Caracterização dos catadores de material reciclável, Sinop/MT, 2015.

\begin{tabular}{|c|c|c|}
\hline Faixa etária & $\mathrm{N}$ & $\%$ \\
\hline $20-30$ & 9 & 37,5 \\
\hline $31-40$ & 6 & 25 \\
\hline $41-50$ & 3 & 12,5 \\
\hline $51-60$ & 4 & 16,7 \\
\hline $61-\mathrm{e}$ mais & 2 & 8,3 \\
\hline Grau de escolaridade & $N$ & $\%$ \\
\hline Analfabeto & 05 & 20,1 \\
\hline Ensino fundamental completo & 00 & 00 \\
\hline Ensino fundamental incompleto & 14 & 58,3 \\
\hline Ensino médio completo & 00 & 00 \\
\hline Ensino médio incompleto & 05 & 20,1 \\
\hline Raça & $\mathrm{N}$ & $\%$ \\
\hline Branco & 09 & 37,5 \\
\hline Preto & 02 & 8,3 \\
\hline Pardo & 13 & 54,2 \\
\hline
\end{tabular}

\begin{tabular}{|c|c|c|}
\hline Estado Civil & $\mathrm{N}$ & $\%$ \\
\hline Solteiro & 04 & 16,7 \\
\hline Casado & 10 & 41,7 \\
\hline Amasiado & 09 & 37,5 \\
\hline Viúvo & 01 & 4,2 \\
\hline Horas de Trabalho & $\mathrm{N}$ & $\%$ \\
\hline $4-5 \mathrm{~h}$ & 02 & 8,3 \\
\hline $6 \mathrm{~h}$ & 05 & 20,8 \\
\hline $8 \mathrm{~h}$ & 05 & 20,8 \\
\hline $10 \mathrm{~h}$ & 06 & 25.0 \\
\hline 12 a 14 hs & 04 & 16,7 \\
\hline$>14 \mathrm{hs}$ & 02 & 8,3 \\
\hline Tempo na Função & $\mathrm{N}$ & $\%$ \\
\hline$<$ de 1 ano & 07 & 29,2 \\
\hline$>$ de 1 ano & 11 & 45,8 \\
\hline 3 a 4 anos & 04 & 16,7 \\
\hline$>$ de 8 anos & 02 & 8,3 \\
\hline Salário & $\mathrm{N}$ & $\%$ \\
\hline$>$ de 1 salário & 07 & 29,2 \\
\hline Até 1 salário & 04 & 16,7 \\
\hline 1-3 salários & 13 & 54,2 \\
\hline
\end{tabular}

Quanto ao sexo, compara-se o resultado ao estudo realizado na cidade de Carpina/PE o qual constatou uma porcentagem de $60 \%$ para o sexo masculino. O baixo grau de escolaridade entre os entrevistados é semelhante em outros trabalhos realizados, reconhecido pelos autores como um dos motivos que dificulta a inclusão das pessoas no mercado formal de trabalho [14-16].

Quanto ao estado civil, mais da metade convivem com outra pessoa, $(41,7 \%)$ sáo casados e $(37,5 \%)$ são amasiados, diferente de estudo previamente realizado, no qual mais da metade eram solteiros [14].

Dos entrevistados, a grande maioria $(45,8 \%)$, atua como catador em torno de 1 a 3 anos, dados diferentes de outros estudos nos quais se evidenciou que mais da metade dos entrevistados exercem essa função entre 5 e 10 anos. Autores defendem que esta atividade ainda é recente $[15,16]$.

A renda mensal gira em torno de 1 a 3 salários mínimos para mais de (50\%) dos entrevistados, percebe-se melhores condições destes quando comparados aos resultados de estudo realizados anteriormente, que revelam que $60 \%$ dos catadores conseguem menos de um salário mínimo [14].

Quando questionados sobre o valor pago pelo material reciclável, observou-se que $66,7 \%$ deles náo sabem o preço real dos utensílios coletados. Os demais $8(33,3 \%)$ responderam com exatidáo acerca 
dos valores para o quilo de cada material, sendo, plástico duro $\mathrm{R} \$ 0.65$, plástico mole $\mathrm{R} \$ 0.50$, pet verde $R \$ 0.70$ a 0.85 , pet branco $R \$ 0.60$, plástico colorido $\mathrm{R} \$ 0.55$, latinhas $\mathrm{R} \$ 0.50$, caixaria $\mathrm{R} \$ 1.00$. Notou-se que a maioria dos entrevistados desconhece com exatidáo o valor pago pelo material coletado, o que pode ser reflexo da falta de organizaçáo por parte da ACAMARES e/ou em decorrência do baixo grau de escolaridade, o faturamento mensal, náo ser um real motivo de interesse para os trabalhadores, conforme visto nas falas.

"O preço abaixo, vendemos para o reciclador e ele abaixa o preço de tudo.” (J.F)

"Eles náo repassam o valor que é pago pelo material arrecadado." (C.P)

"Eu não sei informar, só cato, mas não tem diferença." (A.P. S)

"Varia muito, mas eu não sei o preço." (J. R.B)

Ainda, acerca do conhecimento pode-se inferir a adesão ao uso de EPIs durante a atividade laboral e as respostas obtidas estão demonstradas no gráfico abaixo:

Percebeu-se que pouco mais da metade $(54,2 \%)$ dos entrevistados utilizam protetor solar, $(87,5 \%)$ utilizam luvas, $(95,8 \%)$ fazem uso de botas de borracha e calças compridas, apenas $(29,2 \%)$ faz uso de repelente, $(70,1 \%)$ aderem ao uso de camisas de manga longa e ninguém faz uso de óculos de proteção individual. Ainda, muitos trabalhadores relataram que o protetor solar, luvas, botas e as roupas utilizadas para a catação são encontrados no próprio lixo, durante a catação.

"a gente pega já usada, que vem do frigorífico, não temos condição de compra, usamos do lixo mesmo até a roupa que vestimos". (J.F)

“aqui o que é usado pra se defender é pego no lixo mesmo, usamos as coisa que encontramos no lixo". (R.A.F)

Pesquisa feita em Governador Valadares ressalta que apesar de todos os catadores terem acesso aos EPIs, apenas (14,6\%) os utilizavam. No entanto, em outras pesquisas, percebe-se resultado semelhante a este estudo, nos quais os trabalhadores alegaram náo receber o material e ou adquiri-los por falta de condiçóes, e, por isso, acabam utilizando os provenientes do lixo $[18,19]$.

Figura 1 - (A) trabalhador mostrando luvas e protetor solar encontrado no lixo e que serão utilizados por eles e (B) Trabalhadora desprovida de roupas adequadas para sua proteção, manuseando o fone de ouvido.

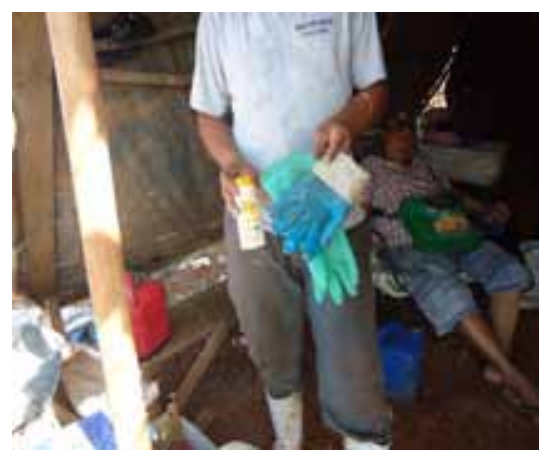

Gráfico I - Utilização de Equipamentos de proteção individual, Sinop/MT, 2015.

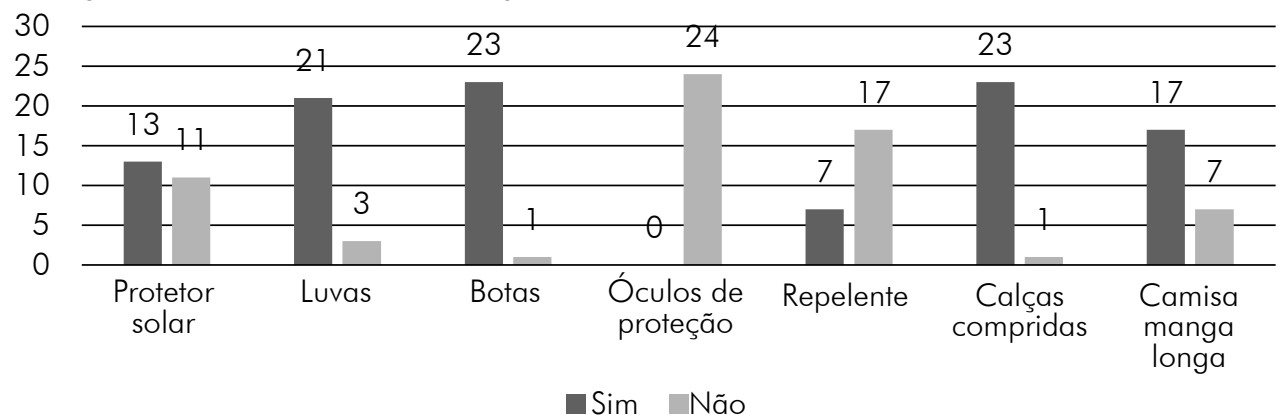




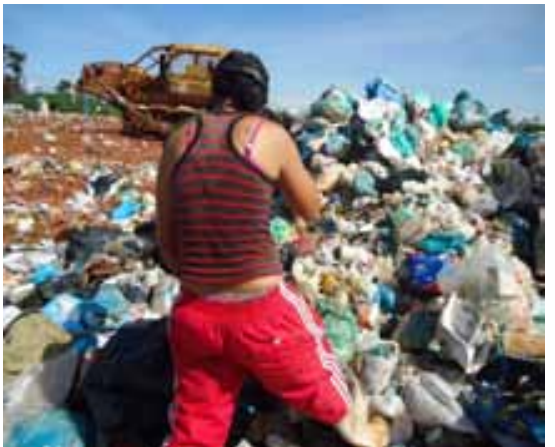

Nesta imagem, podem-se confirmar as respostas, roupas e luvas inadequadas e, ainda, com a mesma luva que desenvolvem suas atividades manipulam objetos em contato com a pele e mucosa, sem perceber e/ou conhecer os riscos à saúde, relacionados a este descuido. A exposição ao lixo por si só é uma condição extremamente insalubre, que acarreta vários e graves danos à saúde humana, pois além dos riscos químicos encontrados neste ambiente, existem também, riscos biológicos, físicos e ergonômicos [10].

Ainda embutido nesta questão foram interrogados sobre o local destinado a separação dos materiais recicláveis. Como se vê, há um elevado percentual de catadores $(87,5 \%)$ que fazem a separaçáo do lixo a céu aberto. Diante das mudanças climáticas, existe o período de chuva e alagamentos, quando se percebe um grande desafio para os trabalhadores, com diminuição da produtividade e consequentemente um comprometimento de sua renda mensal. De acordo com estudos anteriores, este é um dos motivos que ressalvam a importância de uma cooperativa ativa e organizada, para que os trabalhadores não fiquem sem remuneração durante alguns períodos do ano [6].

Neste estudo, 16 (66,7\%) dos entrevistados, afirmam diminuição dos ganhos no período chuvoso e os motivos atrelados ficaram evidentes nas falas.

"É muito difícil catar, as estradas são ruins." (A.P. M)

“Moro longe, é difícil de vir”. (E.P.M.)

"Minha renda fica prejudicada, muito barro." (G.B)

"Cai a produção, mas não é muito, na época da seca se aproveita mais." (A.C.B. C)
A realização do trabalho a "céu aberto" os submete à radiação solar, mudanças de temperatura, chuva, umidade e, ainda, inalaçáo de poeira a qual pode ser a responsável pela irritação crônica da mucosa pulmonar se inspirada por longos períodos. Estas condiçôes favorecem a ocorrência de acidentes de trabalho e doenças, acarretando em prejuízos à saúde física e mental [20].

Figura 2 - Imagem que retrata as condições do local em período de chuva.

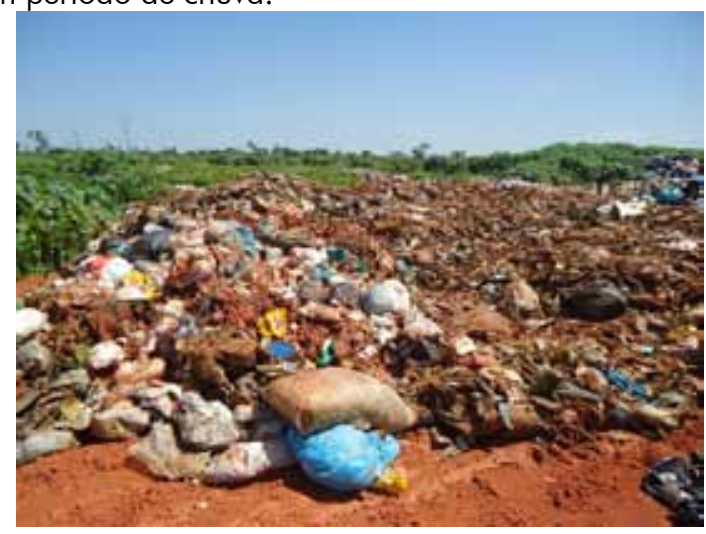

Com relação ao local onde são realizadas as refeiçôes, $19(79,2 \%)$ responderam que se alimentam no local de trabalho, 5 (20,8\%) fazem suas refeiçôes em casa. O aproveitamento do tempo e a distância de casa são os principais motivos pela permanência no local.

"a gente tem que aproveitar os intervalos que vem o caminhão.” (R.A F)

“porque é longe venho de moto.” (E.P. M)

"para ganhar tempo, venho de manhã e volto de noite, se come cuidando para não engoli moscas."(L.F)

"trago de casa o almoço e como no barraco." (A.C.B.C)

Quanto ao descanso no local de trabalho, 22 $(91,7 \%)$ afirmaram descansar no mesmo local que fazem suas refeiçóes, 1 (4,2\%), diz descansar no jerico e $1(4,2 \%)$, descansa no chão.

\footnotetext{
"Quando o caminhão dá uma parada deito no barraco e durmo um sono.” (A.M.S. C)

"Enquanto não vem o caminhão descanso no barraco.” (A.C.B)
} 
"quando o caminhão passa a gente vai catar, descansa no barraco.” (C.S)

"Descanso dentro do meu jerico". (J.A)

O local destinado ao descanso e a alimentaçáo dos catadores são pequenos barracos (Figura III), com presença de moscas, baratas e um cheiro insuportável. Diante deste achado pode-se evidenciar mais uma vez, o quáo expostos estáo a riscos e condiçóes sub-humanas. Esta realidade assemelha-se a grande maioria das cidades brasileiras, notória a necessidade de cooperativas organizadas juntamente com um maior e melhor apoio do poder público e/ou outras entidades sociais no intuito de melhorar as condiçôes de trabalho e consequentemente a qualidade de vida dos envolvidos [6].

Figura 3 - Local destinado à separação do lixo, refeições e descanso.

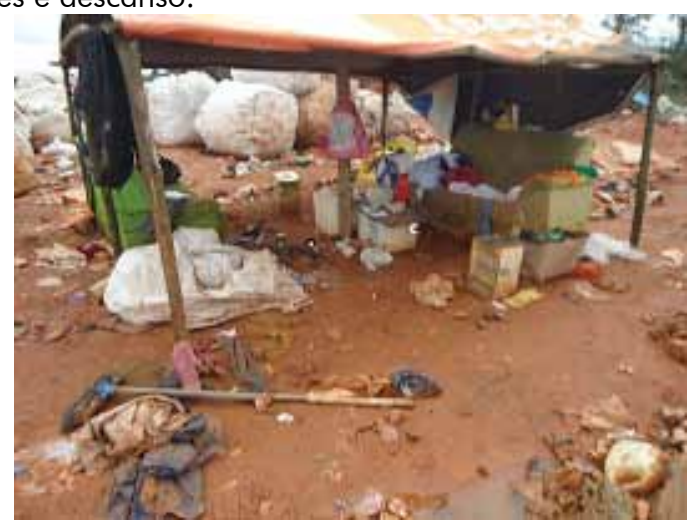

Quanto ao que os levou a escolha da ocupação, $(91,7 \%)$ ressaltam que apesar das dificuldades vivenciadas gostam do trabalho ali desenvolvido, pois os rendimentos são maiores, tem maior liberdade para o cumprimento de horário e melhor adaptação.

"Gosto de trabalhar aqui, procurei outro emprego, mas náo me adaptei.” (C.P.)

"Gosto de trabalhar aqui porque não tem stress, tristeza, a gente se diverte tem pessoas que só riem." (A.C.B.C)

"Sim, aqui a gente trabalha por conta." (A.P. S)

"Sim gosto de trabalhar aqui, procurei outro emprego, mas tenho problema de coluna não aguento trabalhar no pesado." (J. R.B)
"Gosto de trabalhar aqui, já trabalhei de doméstica, não gosto que ninguém manda em mim." (J.C.P.C)

Historicamente o catador de lixo carrega uma condição de excluídos, explorados e vistos como pobres, entretanto desenvolvem um trabalho de suma importância, pois eles recolhem materiais reaproveitáveis como papel, papelão, alumínio, vidros, etc para que sejam processados e fabricados em outros produtos, diminuindo os riscos ao meio ambiente e a demanda de matéria prima.

“[...] já me senti excluído pela sociedade, não dão apoio, tenho 3 filhos vivos, mas eles não me ajudam com nada, a gente se vira da forma como pode, a comida que eu como é achada aqui no lixo [...]". (J. R.B)

"Já me senti excluída pela sociedade, as pessoas acham que não é um serviço digno, é melhor tralhar aqui do que mexer nas coisas dos outros [...]". (J.C.P.C)

"Muitas pessoas ignoram, só que é um lixo limpo. Me sinto orgulhoso de trabalhar aqui, tem muita gente que acha coisas boas aqui". (A.C. B. C)

Compara-se a estudo realizado anteriormente, a maneira como o catador se vê nesta atividade pode interferir nas suas relaçóes com o mundo do trabalho. Muitos direcionam as respostas para o lado positivo da função, pois estão trabalhando honestamente, ao invés de roubar, mendigar ou praticar outros meios para conseguir a sobrevivência e sem perceber, reforçam indiretamente o significado de miséria e exclusão desta atividade [6].

Ao serem questionados sobre as dificuldades vivenciadas no cotidiano laboral, pode-se perceber principalmente a importância que os mesmos dispensam a precariedade das condiçóes de trabalho, e reconhecem os riscos desta atividade.

"Tem que fazer o almoço, vir de bicicleta, a distância, seria bom se tivesse uma cooperativa, um ônibus para pegar-nos, não tem botas, luva, protetor solar, uniforme, adequado [...]". (J.F) 


\begin{abstract}
"A falta de estrutura, máscara, luva aqui é muito perigoso, o pessoal de farmácia manda seringa, curativo... há 30 dias uma mulher furou o pé com agulha e teve que ir para o Pronto Atendimento tirar a agulha que atravessou o dedo, aqui tudo é muito perigoso". (C.P)

"O sol, o perigo, o caco de vidro, material cortante, os beg que tem que arrastar". (L.G.S)
\end{abstract}

Várias são as dificuldades encontradas por estes trabalhadores no cotidiano laboral, os mais comuns são em decorrência das cargas pesadas, ocasionando problemas musculoesqueléticos e até mesmo risco de acidentes, materiais cortantes ou infectados, exposição ao sol, resultando em doenças da pele e ainda, o contato constante com materiais e gases contaminantes responsáveis por problemas respiratórios e gastrointestinais [7].

Figura 4 - (A) Imagem mostrando alimentos retirados do local que servirão para alimentação dos trabalhadores. (B) imagem mostrando a fumaça presente no local, a qual acontece constantemente e é inalada pelos trabalhadores.

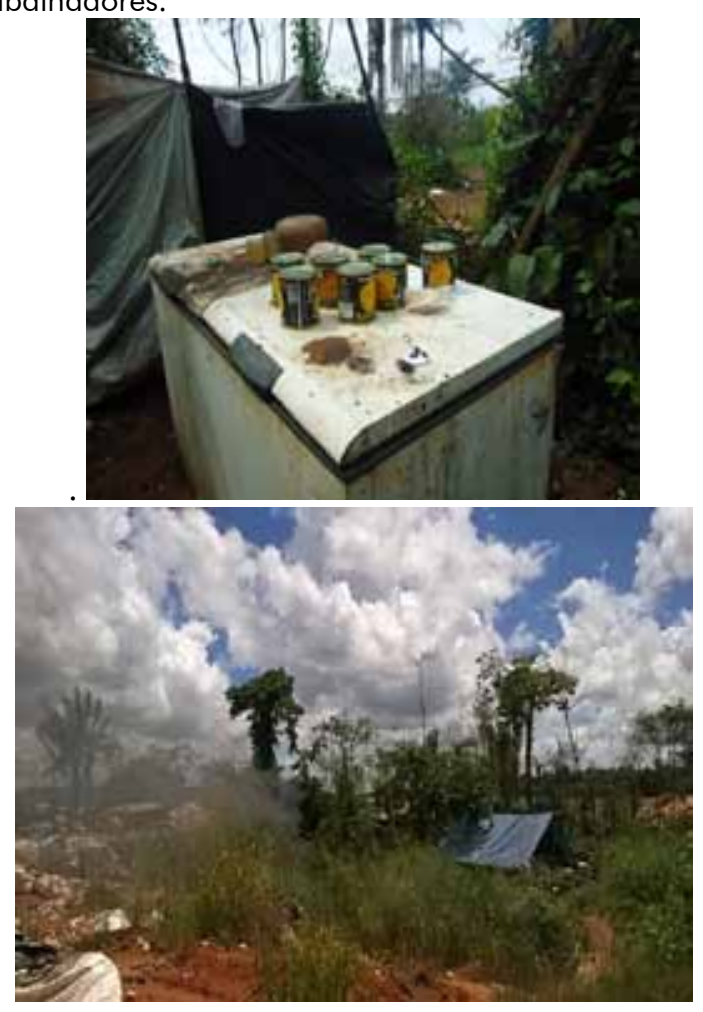

Uma das medidas reconhecidas para um maior e melhor reaproveitamento dos resíduos decorrentes do consumo humano e industrial é conhecida como coleta seletiva do lixo, para a qual, a separaçáo do tipo de material é realizado antes mesmo de sua coleta. Estudos apontam que $90 \%$ dos resíduos sólidos urbanos são reaproveitáveis, entretanto, esta prática ainda está distante da realidade de grande parte dos municípios brasileiros [4].

Devido à falta de adesão desta modalidade de separação e coleta dos resíduos em nosso município, percebe-se a falta de conhecimento preciso por parte dos entrevistados sobre o assunto, 13(54,2\%) responderam que sabem o que é coleta seletiva e 11 $(45,8 \%)$ desconhecem o significado, ainda acerca da importância desta prática, pode-se perceber a falta de informação desta população no que tange aos benefícios para o meio ambiente, à saúde humana e, ainda, no que diz respeito à uma maior produtividade e rentabilidade.

$$
\text { “ão tenho conhecimento. " (J.R.B) }
$$

"Se a seletividade acontecesse na casa." (I.J.B.)

“Separar a reciclagem uma das outras." (J.F)

“Ter um barracão próprio, uma esteira, trabalhar no local coberto.” (A.P)

Para que melhorias aconteçam no sentido de preservação do meio ambiente e saúde humana, tornam-se necessárias açóes eficazes para eliminar os impactos negativos relacionados ao lixo. Com relação à PNRS, percebeu-se que pouco está sendo feito nesse sentido, pois a grande maioria dos entrevistados $17(70,8 \%)$ nunca ouviu falar sobre o assunto, $07(29,2 \%)$ responderam que já ouviram alguma coisa na TV e rádio.

Essa política foi sancionada em 2010, reconhecida com um marco legal e uma importante conquista à classe, pois direciona o planejamento e a gestão dos resíduos no país, tais como a obrigatoriedade de adequação dos municípios para o gerenciamento dos resíduos, prazos para que sejam implantadas maneiras adequadas de processamento dos resíduos e ainda a implantaçáo da coleta seletiva no intuito de amenizar os problemas decorrentes deste inegável e necessário resultado da vida humana. A PNRS ainda destina recursos financeiros para que os catadores de materiais sejam capacitados e a criação de cooperativas ou 
outras formas de associação sejam encorajadas, tornando-a uma atividade mais digna, com menos agravos e uma maior rentabilidade [1].

\section{Conclusão}

Ao término deste trabalho concretizaram-se os objetivos propostos, pôde-se identificar o perfil dos catadores de material reciclável e ainda as precárias condiçóes de trabalho e segurança, visto que os mesmos realizam a alimentação e o descanso sob o barraco onde é realizada muitas vezes a separação dos materiais. Muitos ainda aproveitam alimentos decorrentes do lixo para a alimentação, bem como os EPIs utilizados, porém estes não conferem proteção, já que foram utilizados e desprezados por empresas devido ao desgaste.

Neste contexto, é notória a necessidade de medidas emergentes relacionadas à adesão da PNRS para que os produtos gerados sejam adequadamente reutilizáveis e reciclados, diminuindo não só os riscos à saúde humana e ao meio ambiente como também trazendo melhoria na renda proveniente desta atividade e ainda a conquista de uma profissão dignamente reconhecida. Indispensável, ainda, que os gestores de saúde evidenciem a necessidade de incorporação de estratégias voltadas a esta população no sentido de educar e conscientizar para os riscos à saúde decorrentes da atividade laboral e medidas preventivas.

\section{Referências}

1. Gouveia N. Resíduos sólidos urbanos: impactos socioambientais e perspectiva de manejo sustentável com inclusão social. Ciênc Saúde Coletiva 2012;17(6):150310.

2. Nalini JE. O mercado de reciclagem de lixo no Brasil: entraves ao desenvolvimento [Dissertação]. São Paulo: Pontifícia Universidade Católica; 2008; $120 f$.

3. Instituto Brasileiro de Geografia e Estatística (IBGE). Pesquisa Nacional de Saneamento Básico. Rio de Janeiro: IBGE; 2010. 219 p.

4. Prates CI. Tem algo podre no lixo: A coleta seletiva do lixo em hospitais públicos de Brasília [Dissertação]. Rio de Janeiro: Fiocruz Fundação Oswaldo Cruz; 2011.

5. Brasil. Lei no 12.305, de 2 de agosto de 2010, que institui à Politica Nacional de Resíduos Sólidos: altera a lei no 9.605, de 12 de fevereiro de 1998; e dá outras providencias. [citado 2014 Out 6]. Disponível em
URL: http://www.mma.gov.br/port/conama/legiabre. cfm?codlegi $=636$.

6. Gonçalves VC, Malafaia G, Castro ALS, Veiga BGA. A vida no lixo: Um estudo de caso sobre os catadores de materiais recicláveis no Município de Ipameri. Holos 2013;29(12):238-50.

7. Maciel RH, Matos TGR, Borsoi ICF, Mendes ABC, Siebra PT, Mota CA. Precariedade do trabalho e da vida de catadores de recicláveis em Fortaleza. Arquivos Brasileiros de Psicologia 2011;63(8):71-82.

8. Ferraz L, Gomes MHA, Busato MA. O catador de materiais recicláveis: um agente ambiental. Caderno EBAPR BR 2012;10(3)763-8.

9. Siqueira MM. Moraes MS. Saúde coletiva, resíduos sólidos urbanos e os catadores de lixo. Ciênc Saúde Coletiva 2007;14(6):2115-22.

10. Cavalcante $S$, Franco AFM. Profissão perigo: percepção de risco à saúde entre os catadores do lixo do jangurussu. Rev Mal-Estar e Subjetividade 2007;7(1):211-31.

11. Ramos GMM. Importância do uso dos equipamentos de proteçáo individual para os catadores de lixo [Monografia]. Salvador: Atualiza Associação Cultural; 2012. $31 \mathrm{f}$.

12. 12. IBGE. Pesquisa Nacional de Saneamento Básico. Rio de Janeiro: IBGE; 2010. p. 219.

13. Minayo MCS. O desafio do conhecimento: pesquisa qualitativa em Saúde. São Paulo: Hucitec; 2006. 406 p.

14. Kirchner RM, Saidelles APF, Stumm EMF. Percepçóes e perfil dos catadores de materiais recicláveis de uma cidade do RS. Revista Brasileira de Gestão e Desenvolvimento Regional 2009;5(3):221-32.

15. Martins AC. A Busca de proteçáo ao trabalho dos catadores de lixo recicláveis: análise da experiência do Instituto lixo e Cidadania em Curitiba, PR [Dissertação]. Ponta Grossa: Universidade Federal de Ponta Grossa; 2007.

16. Bosi APA. A organização capitalista do trabalho "informal": o caso dos catadores de recicláveis. Revista Brasileira de Ciências Sociais 2008;23(67).

17. Ferreira SL. Os "catadores do lixo" na construção de uma nova cultura: a de separar o lixo e da consciência ambiental. Rev Urutágua - Revista Acadêmica Multidisciplinar 2005;(7).

18. Hoefel MG, Carneiro FF, Santos L M P, Gubert MB, Amate EM, Santos W Acidentes de trabalho e condiçóes de vida de catadores de resíduos sólidos recicláveis no lixão do Distrito Federal. Rev Bras Epidemiol 2013;16(3).

19. Pereira ER, Silva RMCRA, Mello FP, Oliveira DC, Silva MA. Representaçóes Sociais dos catadores de um aterro Sanitário: o convívio com o lixo. Psicologia: teoria e prática 2012;14(3)33-47.

20. Cordeiro CJD, Pereira OS, Duarte AE, Barros LM, Souza MM. Prejuízos causados aos catadores que trabalham no lixão do Munícipio de Juazeiro do Norte-CE. Enciclopédia Biosfera, Centro Científico Conhecer 2012;8(15):2555. 